nephron

Practice
Nephron 2019;143:188-192

DOI: $10.1159 / 000502381$
Received: April 9, 2019

Accepted after revision: July 25, 2019

Published online: September 18, 2019

\title{
Comprehensive Assessment of Kidney Health in Acute Kidney Injury: Can It Be Achieved?
}

\author{
Etienne Macedo ${ }^{a}$ b Camila Lima ${ }^{b}$ \\ aDivision of Nephrology, Department of Medicine, University of California San Diego, San Diego, CA, USA; \\ ${ }^{b}$ LIM 12, Division of Nephrology, University of Sao Paulo Medical School, Sao Paulo, Brazil
}

\section{Keywords}

Biomarkers · Acute kidney injury

\begin{abstract}
Acute kidney injury (AKI) is a frequent event in hospitalized patients, with an incidence that continues to rise, reaching as high as $70-80 \%$ in intensive care settings. The need for dialysis and progression to end-stage kidney disease (ESKD) after an episode of AKI is relatively low, from 5 to $20 \%$. However, it is now recognized that patients with AKI may have very different kidney outcomes, varying from complete recovery, incipient chronic kidney disease (CKD), to progression to ESKD. Recent studies have shown that even mild AKI episodes can be associated with a $90 \%$ increased risk of developing CKD during long-term follow-up. There is a significant need to focus our efforts on factors that could mitigate the progression of kidney dysfunction and ultimately improve outcomes from AKI. The first step toward this goal encompasses a better understanding of tubular and glomerular alterations during and following an AKI episode. Our current approach, based solely on glomerular filtration rate (GFR), is flawed, since the loss of kidney function does not correspond to the degree of decline in estimated GFR (eGFR), and eGFR does not reflect tubular function. Changes in tubular concentration, reabsorptive and secretory capacity are recognized in AKI; however, they have not been incorporat-
\end{abstract}

ed in clinical assessments of overall kidney function. Here we review a few candidates to assess glomerular filtration/permeability, tubular dysfunction, and injury and how we expect these markers to alter during the development and recovery phase of AKI.

(c) 2019 S. Karger AG, Basel

\section{Introduction}

Recent advances in urinary and serum biomarkers of kidney damage have provided new tools to identify tubular injury that can be mapped to specific sites; however, these injury markers have not been correlated with alterations in tubular function [1]. The combination of tubular function assessment in conjunction with kidney injury, glomerular filtration, and permeability markers would provide a more accurate overall evaluation of kidney health [2]. This overall assessment would enable cli-

Contribution from the AKI and CRRT 2019 Symposium at the 24th International Conference on Advances in Critical Care Nephrology, Manchester Grand Hyatt, San Diego, CA, USA, February 26 - March 1, 2019. This symposium was supported in part by the NIDDK funded University of Alabama at Birmingham-University of California San Diego O'Brien Center for Acute Kidney Injury Research (P30DK079337).

\section{KARGER}

(c) 2019 S. Karger AG, Basel

E-Mail karger@karger.com

www.karger.com/nef
Etienne Macedo

Division of Nephrology, UC San Diego

9452 Medical Center Drive

San Diego, CA 92037 (USA)

E-Mail emmacedo@ ucsd.edu 
Table 1. Biomarkers rational for clinical use in acute kidney injury setting and/or CKD

\begin{tabular}{|c|c|c|c|}
\hline Biomarkers & & Mechanism in AKI & Limitations/confounding factors \\
\hline \multirow[t]{2}{*}{$\begin{array}{l}\text { Functional/ } \\
\text { filtration }\end{array}$} & $\mathrm{sCr}$ & $\begin{array}{l}\text { Freely filtered by glomerulus, also secreted } \\
\text { by tubular cells }\end{array}$ & $\begin{array}{l}\text { Affected by age, gender, muscle mass, muscle metabolism, } \\
\text { medication, hydration status, sepsis and liver disease }\end{array}$ \\
\hline & Cys C & $\begin{array}{l}\text { Freely filtered by glomerulus, reabsorbed } \\
\text { and metabolized in the proximal tubular cells }\end{array}$ & $\begin{array}{l}\text { Affected by age, high glucocorticoids levels, systemic } \\
\text { inflammation, cigarette smoking, hyperbilirubinemia, } \\
\text { hypertriglyceridemia, malignance and thyroid and } \\
\text { proliferative disorders }\end{array}$ \\
\hline $\begin{array}{l}\text { Permeability/ } \\
\text { tubular injury }\end{array}$ & Albuminuria & $\begin{array}{l}\text { Filtered by glomerulus, reabsorbed and metabolized } \\
\text { in the proximal renal tubule; prediction of } \\
\text { cardiovascular risk and CKD progression }\end{array}$ & $\begin{array}{l}\text { Affected by protein metabolism (drugs or liver diseases) } \\
\text { and cardiovascular disease }\end{array}$ \\
\hline Tubular injury & KIM-1 & $\begin{array}{l}\text { Transmembrane glycoprotein produced after ischemic } \\
\text { /nephrotoxic insults; is increased in AKI and associated } \\
\text { with CKD progression (fibrosis) }\end{array}$ & $\begin{array}{l}\text { Increase in renal cell carcinoma, chronic proteinuria, } \\
\text { CKD and sickle cell nephropathy }\end{array}$ \\
\hline $\begin{array}{l}\text { Tubular } \\
\text { inflammation }\end{array}$ & IL-18 & $\begin{array}{l}\text { Pro-inflammatory cytokine; increased in ischemic and } \\
\text { inflammatory AKI }\end{array}$ & $\begin{array}{l}\text { Affected by other factors including; psoriasis, heart failure, } \\
\text { inflammatory bowel disease, multiple sclerosis and } \\
\text { metastatic melanoma }\end{array}$ \\
\hline Tubular stress & $\begin{array}{l}\text { TIMP-2/ } \\
\text { IGFBP7 }\end{array}$ & $\begin{array}{l}\text { Proteins released in urine in response to stress } \\
\text { (inflammation and ischemia); useful in AKI prediction }\end{array}$ & $\begin{array}{l}\text { Also increases in inflammation, ischemic events in other } \\
\text { organs and cancer (prostate, colorectal) }\end{array}$ \\
\hline Reabsorption & $\alpha 1 \mathrm{~m}$ & $\begin{array}{l}\text { Low molecular weight protein, its presence reflects } \\
\text { proximal tubular damage; studies in nephrotoxic AKI } \\
\text { and CKD progression }\end{array}$ & $\begin{array}{l}\text { Is found in other tissues: lungs, intestine and placenta and } \\
\text { could be affected in sepsis }\end{array}$ \\
\hline Secretion & $\begin{array}{l}\text { Fe } \\
\text { hippurate }\end{array}$ & $\begin{array}{l}\text { Handle by organic anion transporters on the basolateral } \\
\text { membrane, decreased secretion reflects tubular } \\
\text { dysfunction. Low excretion has been associated } \\
\text { with CKD progression }\end{array}$ & $\begin{array}{l}\text { Obesity, diabetes, gastrointestinal diseases, psychological } \\
\text { disorders, autism, toxicity and parasitic infection affect } \\
\text { excretion }\end{array}$ \\
\hline
\end{tabular}

sCr, serum creatinine; AKI, acute kidney injury; CKD, chronic kidney disease; eGRF, estimated glomerular rate filtration; Cys C, cystatin C; Pro-enk, Proenkephalin; Alb, albuminuria; KIM-1, kidney injury olecule-1; NGAL, neutrophil gelatinase associated a lipocalin; IL-18, interlekine-18; TIMP-2, Tissue inhibitor of metalloproteinase 2; IGFBP 7, Insulin-like growth factor-binding protein 7; alm, al-microglobulin; Fe, fractional excretion; HA, hipurate.

nicians to be better equipped to diagnose kidney disease and manage patients with kidney dysfunction [3-5].

Despite the improvement in acute kidney injury (AKI) classification systems and putative biomarkers for AKI, timely diagnosis and assessment of AKI severity remain challenging [6]. Alterations in kidney function are generally assessed by serum creatinine ( $\mathrm{sCr}$ ), the most common surrogate for glomerular filtration rate (GFR), which has limitations since GFR poorly reflect tubular function, the main site of injury in AKI. Renal tubule cells perform many of the essential kidney functions, including reabsorption, electrolyte transport, secretion of endogenous molecules and medications, acid/base balance control, and concentration and dilution of urine [7]. In this mini review, we will discuss some key pathophysiological mechanisms and key markers of kidney glomerular and tubular function, including filtration, absorption, secretion, and concentration that could provide a comprehensive evaluation of kidney function (Table 1).

\section{The Concern about the Limitation of $s \mathrm{Cr}$ and the \\ Difficulty to Find a Reliable GFR}

Our most recent diagnostic criteria for AKI, the KDIGO classification system [8], still relies on changes of sCr and urine output [9]. sCr has standardized assays widely available and is of easy interpretation by all providers. However, $\mathrm{sCr}$ is not only filtered but also secreted by the tubules, and affected by age, gender, muscle mass, 
muscle metabolism, medication, and hydration status [10]. Thus, sCr- based evaluation of filtration is inaccurate. The more precise exogenous markers of filtration, inulin, iothalamate, CrEDTA or iohexol, can provide more reliable filtration estimation, but need to be injected, making the process time consuming and costly.

\section{Urine and Plasma Uromodulin as a Marker of}

\section{Tubular Reserve}

Uromodulin, also called Tamm-Horsfall protein, is a glycoprotein expressed in the thick ascending limb and distal convoluted tubule of the kidneys. It is excreted as the most abundant urinary protein in healthy kidneys [11], and released into the circulation through the peritubular capillary network $[12,13]$. Different than other markers for kidney function, uromodulin is exclusively produced by thick ascending limb cells, and thus it can be linked to tubular health and reserve [14-16]. Levels of urine and serum uromodulin has been correlated with kidney health and few experimental studies have suggested that it may a down regulation effect on systemic and kidney inflammation, playing a protective role in AKI [17]. In cardiac surgery, studies have shown that low urine uromodulin is associated with higher odds of AKI and higher peak sCr in the postoperative period $[18,19]$. Plasma uromodulin can also be assessed and have 2 main advantages: less prone to enzymatic degradation by proteases [20] and does not require correction for urinary concentration [21].

\section{Plasma Cystatin C: More Accurate Filtration Marker}

Cystatin C (Cys C) is a low molecular weight, 13.36 $\mathrm{kDa}$ non-glycosylated protein, freely filtered through the glomerulus, reabsorbed and metabolized in the proximal renal tubule, not suffering renal or extrarenal secretion. Unlike creatinine, serum levels of Cys $\mathrm{C}$ are not significantly affected by sex, race or muscle mass. However, concentrations of Cys $\mathrm{C}$ are affected by age, high glucocorticoids levels, thyroid disorders, inflammation, cigarette smoking, and some proliferative disorders. In addition, in sepsis, the production of Cys $\mathrm{C}$ is decreased, and the nonrenal clearance is increased.

Proenkephalin is an Early Biomarker of Kidney Injury Not Influenced by Inflammation

Proenkephalin (proENK) is a monomeric peptide (approximately $4.5 \mathrm{kDa}$ ). It is a stable surrogate marker for endogenous enkephalins; it is cleaved from the precursor peptide preproenkephalin A alongside enkephalins (endogenous opioids) and filtrated by the glomerulus. PENK has been associated with the worsening of kidney during AKI and accurately represents GFR in patients with sepsis. In a retrospective study including 101 patients admitted to the emergency department with suspected sepsis, in patients without AKI, ENK levels were mainly within the normal range, despite the presence of inflammation [22]. In the postoperative period of cardiac surgery, proENK was an early marker of AKI development, while NGAL was elevated above the normal range for almost all patients without AKI [23].

\section{Albuminuria as a Marker of Glomerular and Tubular Dysfunction}

Urine albumin is a well-known marker glomerular permeability. The structure of the fenestrated endothelial layers, negative charge basement membrane, and podocytes do not allow albumin to enter the tubule. The presence of albumin in the urine reflects damage to this delicate and complex structure, being a useful marker of endothelial dysfunction, chronic kidney disease (CKD) progression, and an independent risk factor for cardiovascular disease and cardiovascular mortality [24-26]. However, the mechanism of albuminuria is complex as the normal glomerulus filters substantial amounts of albumin that is then processed by proximal tubular cells. Dysfunction in retrieval pathway dysfunction is associated with nephrotic range proteinuria. A small amount of filtered albumin that is not retrieved undergoes lysosomal degradation. In AKI, the dysfunction in the degradation pathway can lead to non-nephrotic proteinuria, and be a marker of tubular dysfunction as well.

\section{Urinary Cystatin as a Marker of Tubular Injury}

Serum Cys C is a more accurate marker of glomerular filtration, whereas urinary Cys $\mathrm{C}$ can be an early marker in tubular injury. Few studies have shown that serum Cys $\mathrm{C}$ can provide an earlier AKI diagnosis than sCr [27]. In the study by Park et al. [28] the urinary Cys $\mathrm{C}$ and creatinine were measured in 213 patients with AKI diagnosis, classified as pre-renal AKI and intrinsic AKI. The authors found that values of urinary Cys C increased in intrinsic AKI. Contradictory findings were reported in other studies. Royakkers et al. [29], found that urinary Cys $\mathrm{C}$ had no diagnostic value in the days prior to the diagnosis of AKI by sCr $(\mathrm{AUC}<0.50)$ and the plasma and urinary Cys $\mathrm{C}$ on the first day of AKI diagnosis were poor predictors of the need for dialysis (AUC 0.66). 
Changes in Urine $\alpha 1$-Microglobulin Levels Are

Associated with Tubular Exposure to Nephrotoxin

In contrast to other biomarkers produced by proximal tubular epithelial cells, $\alpha 1-$ microglobulin ( $\alpha 1 \mathrm{~m})$, a $26-\mathrm{kD}$ lipocalin, is filtered at the glomerulus but fully reabsorbed by proximal tubular epithelial cells, where it is degraded. With kidney tubule dysfunction, elevated urine a $1 \mathrm{~m} \mathrm{lev-}$ els indicate decreased proximal tubular reabsorptive capacity. Utilizing samples from Multicenter AIDS Cohort Study, a large cohort of men with normal kidney function and HIV infection, Jotwani et al. [30], showed the association of tenofovir (TDF) exposure and higher urine levels of a $1 \mathrm{~m}$. Among HIV-infected men, cumulative TDF exposure was associated with incrementally higher a $1 \mathrm{~m}$ levels, whereas time since TDF treatment discontinuation was associated with progressively lower a $1 \mathrm{~m}$ levels.

These findings, in conjunction with the prior work demonstrating the prognostic significance of urine $\alpha 1 \mathrm{~m}$ for CKD progression, highlight $\alpha 1 \mathrm{~m}$ as a promising biomarker of tubular function compromise.

\section{Urine Hippurate Levels Can Estimate Tubular}

Secretion Function

The combination of protein-binding and tubular secretion allows the kidney to clear some solutes at rates exceeding the renal plasma flow, and thus, is a more efficient mechanism than glomerular filtration and especially important for drug elimination. In a study using an untargeted mass spectrometry approach in healthy controls and dialysis patients, 13 endogenous solutes that are efficiently cleared by renal tubule secretion were identified [31]. Hippurate, was found to have a renal clearance 12fold higher than $\mathrm{sCr}$ in healthy controls (mean hippurate clearance $1,868 \mathrm{~mL} / \mathrm{min}$ ), and was elevated $>30$ fold in dialysis patients relative to healthy controls. Similar to para-amino hippurate, hippurate is known to be actively secreted into the urinary filtrate by proximal tubule cells, and yet, unlike para-amino hippurate, hippurate is an endogenous compound that can be measured in serum and urine in humans without the need for intravenous loading. In a prospective cohort study of 298 patients with kidney disease, hyppurate was measured by liquid chromatography-tandem mass spectrometric assays, in serum and timed urine samples [32]. They show that tubular secretion rate modestly correlated with mGFR and was associated with fractional excretion of electrolytes. Lower levels of hippurate in the urine were associated with higher risk of death independent of estimated GFR. Thus, measuring tubular secretion may add information on overall kidney health.

Comprehensive Assessment of Kidney

Health in AKI: Can It Be Achieved?
Of note, in a small study, tubular secretion function assessment by spot serum and urine samples was compared with 24-h urine samples [33]. Fractional excretion of tubular secretion markers were shown to be relatively stable, supporting the use of spot urine specimens to assess tubular secretion.

\section{Lower Urine Ammonium Measured in Spot Urine}

Samples can Reflect Decreased Tubular Function

In patients with CKD, the ability to adapt urinary ammonia excretion to increased or normal acid load is impaired. In a cohort study with 1,065 patients CKD stages $1-4$, GFR by $51 \mathrm{Cr}-\mathrm{EDTA}$, venous total $\mathrm{CO}_{2}$ concentration and urinary ammonia excretion were assessed, over $24 \mathrm{~h}$ and in fasting spot samples, for a median follow-up period of 4.3 years [34]. Urinary ammonia concentration (in spot urine) decreased with GFR; for every $10 \mathrm{mEq} / \mathrm{L}$ decrease in fasting NH4 urinary concentration. As the net endogenous acid production was the same at any mGFR level, the decrease in ammonia was likely due to an impaired ability of the tubules to generate ammonium and not a consequence of decreased acid load. Similar associations with CKD progression and death were found using 24-h urine or spot specimens. In acute worsening of kidney function, low ammonium may reflect a decreased ability of the tubules to generate ammonium, or perhaps to secrete hydrogen and keep ammonium in the urinary space.

\section{Conclusion}

The sequential assessment of the components of tubular health, before and during the course of AKI, could provide us with a unique opportunity to understand their pattern during AKI. The panel biomarkers discussed above offer a more comprehensive assessment of kidney health. Understanding the pattern of change of the components of tubular function and its correlation with tubular injury during an AKI episode can provide insights into the etiology and prognosis of AKI. Knowledge of the degree of dysfunction on the different components of tubular function can have clinical implications in drug dosing and prevention of toxicity. Whether the assessment of overall tubular health can improve the prediction of severity, non-recovery, and risk of CKD progression is still a challenge for the AKI research field.

\section{Disclosure Statement}

The authors declare no conflicts of interest, financial or otherwise.

Nephron 2019;143:188-192 


\section{References}

1 Endre ZH, Kellum JA, Di Somma S, Doi K, Goldstein SL, Koyner JL, et al. Differential diagnosis of AKI in clinical practice by functional and damage biomarkers: workgroup statements from the tenth Acute Dialysis Quality Initiative Consensus Conference. Contrib Nephrol. 2013;182:30-44.

2 Murray PT, Mehta RL, Shaw A, Ronco C, Endre Z, Kellum JA, et al.; ADQI 10 workgroup. Potential use of biomarkers in acute kidney injury: report and summary of recommendations from the 10th Acute Dialysis Quality Initiative consensus conference. Kidney Int. 2014 Mar;85(3):513-21.

3 Matzke GR, Aronoff GR, Atkinson AJ Jr, Bennett WM, Decker BS, Eckardt KU, et al. Drug dosing consideration in patients with acute and chronic kidney disease-a clinical update from Kidney Disease: Improving Global Outcomes (KDIGO). Kidney Int. 2011 Dec; 80(11):1122-37.

4 Cruz DN, Bagshaw SM, Maisel A, Lewington A, Thadhani R, Chakravarthi R, et al. Use of biomarkers to assess prognosis and guide management of patients with acute kidney injury. Contrib Nephrol. 2013;182:45-64.

5 Garimella PS, Katz R, Ix JH, Fried LF, Kritchevsky SB, Devarajan P, et al. Association of urinary uromodulin with kidney function decline and mortality: the health $\mathrm{ABC}$ study. Clin Nephrol. 2017 Jun;87(6):278-86.

6 Malhotra R, Siew ED. Biomarkers for the Early Detection and Prognosis of Acute Kidney Injury. Clin J Am Soc Nephrol. 2017 Jan; 12(1):149-73.

7 Ronco C, Chawla LS. Glomerular and Tubular Kidney Stress Test: New Tools for a Deeper Evaluation of Kidney Function. Nephron. 2016;134(3):191-4.

8 Section 2: AKI Definition. Kidney Int Suppl (2011). 2012;2(1):19-36.

9 Chapter 1: Definition and classification of CKD. Kidney Int Suppl (2011). 2013;3(1):1962.

10 Brown RS Jr, Lombardero M, Lake JR. Outcome of patients with renal insufficiency undergoing liver or liver-kidney transplantation. Transplantation. 1996 Dec;62(12): 1788-93.

11 El-Achkar TM, Wu XR. Uromodulin in kidney injury: an instigator, bystander, or protector? Am J Kidney Dis. 2012 Mar;59(3):45261.

12 Micanovic R, Khan S, Janosevic D, Lee ME, Hato T, Srour EF, et al. Tamm-Horsfall Protein Regulates Mononuclear Phagocytes in the Kidney. J Am Soc Nephrol. 2018 Mar; 29(3):841-56.
13 El-Achkar TM, McCracken R, Liu Y, Heitmeier MR, Bourgeois S, Ryerse J, et al. TammHorsfall protein translocates to the basolateral domain of thick ascending limbs, interstitium, and circulation during recovery from acute kidney injury. Am J Physiol Renal Physiol. 2013 Apr;304(8):F1066-75.

14 Leiherer A, Muendlein A, Saely CH, Brandtner EM, Geiger K, Fraunberger P, et al. The value of uromodulin as a new serum marker to predict decline in renal function. J Hypertens. 2018 Jan;36(1):110-8.

15 Scherberich JE, Gruber R, Nockher WA, Christensen EI, Schmitt H, Herbst V, et al. Serum uromodulin-a marker of kidney function and renal parenchymal integrity. Nephrol Dial Transplant. 2018 Feb;33(2):284-95.

16 Micanovic R, LaFavers K, Garimella PS, Wu XR, El-Achkar TM. Uromodulin (TammHorsfall protein): guardian of urinary and systemic homeostasis. Nephrol Dial Transplant. 2019, Epub ahead of print.

17 El-Achkar TM, Wu XR, Rauchman M, McCracken R, Kiefer S, Dagher PC. TammHorsfall protein protects the kidney from ischemic injury by decreasing inflammation and altering TLR4 expression. Am J Physiol Renal Physiol. 2008 Aug;295(2):F534-44.

18 Garimella PS, Jaber BL, Tighiouart H, Liangos O, Bennett MR, Devarajan P, et al. Association of Preoperative Urinary Uromodulin with AKI after Cardiac Surgery. Clin J Am Soc Nephrol. 2017 Jan;12(1):10-8.

19 Bennett MR, Pyles O, Ma Q, Devarajan P. Preoperative levels of urinary uromodulin predict acute kidney injury after pediatric cardiopulmonary bypass surgery. Pediatr Nephrol. 2018 Mar;33(3):521-6.

20 Youhanna S, Weber J, Beaujean V, Glaudemans B, Sobek J, Devuyst O. Determination of uromodulin in human urine: influence of storage and processing. Nephrol Dial Transplant. 2014 Jan;29(1):136-45.

21 McMahon GM, Waikar SS. Biomarkers in nephrology: core Curriculum 2013. Am J Kidney Dis. 2013 Jul;62(1):165-78.

22 Marino R, Struck J, Hartmann O, Maisel AS, Rehfeldt M, Magrini L, et al. Diagnostic and short-term prognostic utility of plasma proenkephalin (pro-ENK) for acute kidney injury in patients admitted with sepsis in the emergency department. J Nephrol. 2015 Dec; 28(6):717-24.

23 Shah KS, Taub P, Patel M, Rehfeldt M, Struck J, Clopton P, et al. Proenkephalin predicts acute kidney injury in cardiac surgery patients. Clin Nephrol. 2015 Jan;83(1): 29-35.
24 Gerstein HC, Mann JF, Yi Q, Zinman B, Dinneen SF, Hoogwerf B, et al.; HOPE Study Investigators. Albuminuria and risk of cardiovascular events, death, and heart failure in diabetic and nondiabetic individuals. JAMA. 2001 Jul;286(4):421-6.

25 Feldt-Rasmussen B. Microalbuminuria, endothelial dysfunction and cardiovascular risk. Diabetes Metab. 2000 Jul;26 Suppl 4:64-6.

26 Vishram JK, Dahlöf B, Devereux RB, Ibsen H, Kjeldsen SE, Lindholm LH, et al. Blood pressure variability predicts cardiovascular events independently of traditional cardiovascular risk factors and target organ damage: a LIFE substudy. J Hypertens. 2015 Dec;33(12): 2422-30

27 Aydoğdu M, Gürsel G, Sancak B, Yeni S, Sarı $\mathrm{G}$, Taşyürek $S$, et al. The use of plasma and urine neutrophil gelatinase associated lipocalin (NGAL) and Cystatin C in early diagnosis of septic acute kidney injury in critically ill patients. Dis Markers. 2013;34(4): 237-46.

28 Park MY, Choi SJ, Kim JK, Hwang SD, Lee YW. Urinary cystatin C levels as a diagnostic and prognostic biomarker in patients with acute kidney injury. Nephrology (Carlton). 2013 Apr; 18(4):256-62.

29 Royakkers AA, Korevaar JC, van Suijlen JD, Hofstra LS, Kuiper MA, Spronk PE, et al. Serum and urine cystatin $\mathrm{C}$ are poor biomarkers for acute kidney injury and renal replacement therapy. Intensive Care Med. 2011 Mar;37(3): 493-501.

30 Jotwani V, Scherzer R, Estrella MM, Jacobson LP, Witt MD, Palella FJ Jr, et al. HIV Infection, Tenofovir, and Urine a1-Microglobulin: A Cross-sectional Analysis in the Multicenter AIDS Cohort Study. Am J Kidney Dis. 2016 Oct;68(4):571-81.

31 Sirich TL, Aronov PA, Plummer NS, Hostetter TH, Meyer TW. Numerous proteinbound solutes are cleared by the kidney with high efficiency. Kidney Int. 2013 Sep;84(3): $585-90$.

32 Suchy-Dicey AM, Laha T, Hoofnagle A, Newitt R, Sirich TL, Meyer TW, et al. Tubular Secretion in CKD. J Am Soc Nephrol. 2016 Jul;27(7):2148-55

33 Garimella PS, Li K, Naviaux JC, Shlipak MG, Abdelmalek JA, Castro E, et al. Utility of Spot Urine Specimens to Assess Tubular Secretion. Am J Kidney Dis. 2017 May;69(5):709-11.

34 Vallet M, Metzger M, Haymann JP, Flamant M, Gauci C, Thervet E, et al.; NephroTest Cohort Study group. Urinary ammonia and long-term outcomes in chronic kidney disease. Kidney Int. 2015 Jul;88(1):137-45. 